\title{
THE EFFECTS OF PLAY-BASED LEARNING ON EARLY CHILDHOOD EDUCATION AND DEVELOPMENT
}

\author{
Erah Ali1, Kaitlyn M. Constantino², Azhar Hussain³, Zaiba Akhtar
}

${ }_{1}^{1}$ Research Scholar, Department of Psychology, City College, The City University of New York, New York, USA.

2Early Education and Special Education Teacher, Department of Education, Brooklyn College, The City University of New York, New York, USA.

3Medical Student, Department of Medicine, Xavier University School of Medicine, Aruba.

${ }^{4}$ Medical Student, Department of Medicine, Xavier University School of Medicine, Aruba.

\begin{abstract}
\section{BACKGROUND}

The "sooner-the-better" is the perfect catch phrase for early childhood education. The early childhood education is a powerful methodology acting as a medium to promote continued success in school, workplace and also in social and civic realms. Very little attention has been taken into consideration to the psychological and sociological values of play-based learning in early childhood. Researchers from education and psychology have suggested 'play' is a sturdy mediator of learning various skills throughout a person's life. This is in correspondence to Piagetian, which has significantly influenced developmentally appropriate practice. It includes the perspective that children learn 'naturally' through play with the teachers facilitating opportunities for play in the environment they are exposed to. Children taught at an early age usually benefit in the following ways such as improved social skills, lesser or no need for special education instruction during subsequent school years, better grades and enhanced attention spans. If a child lags in those early periods of early education, chances are they might face difficulties in catching up.

This paper aims at providing an overview of research and theory relayed to play in the early educational system, the stepwise progression and its benefits in structuring the children's lives in diverse ways.
\end{abstract}

\section{Methodology}

For this study, the descriptive research method was used. The information was obtained from review articles from databases.

\section{KEY WORDS}

Development, Play-Based Learning, Education, Early Childhood Education.

HOW TO CITE THIS ARTICLE: Ali E, Constantino KM, Hussain A, et al. The effects of play-based learning on early childhood education and development. J. Evolution Med. Dent. Sci. 2018;7(43):4682-4685, DOI: 10.14260/jemds/2018/1044

\section{BACKGROUND}

The first day of Kindergarten marks the child's first steps into the journey of pursuing an education. Looking back upon your own experience, you reflect and think of the most meaningful memory that comes to mind: What was enjoyable about this experience? What was most impactful on your life? You are reminded of changes you have made socially as a result of your earliest educational experiences and how you have felt progressing through your academic experiences. It is valuable to view the experiences one may gain throughout their schooling from the first-hand perspective of a child and the reflective perspective as an adult. Those who are in the early childhood programs (from birth through eight-yearsold), spend an average of 40-h per week in school and other educational programs. That is approximately $41 \%$ of their week if you consider them to have a 14-h day. ${ }^{1}$ This exposure to day-care, after-school, public school, tutoring etc. allows ample opportunity for children to gain access to socialisation experiences as well as cognitive and physical development opportunities.

'Financial or Other Competing Interest': None.

Submission 03-09-2018, Peer Review 03-10-2018,

Acceptance 09-10-2018, Published 22-10-2018.

Corresponding Author:

Erah Ali,

City College,

The City University of New York,

New York, U. S. A.

E-mail: erah.ali96@gmail.com

DOI: $10.14260 /$ jemds/2018/1044
The cognitive skills of children are still in their early phase of inception and it is important to emphasise value of play-based learning during this developmental period.

This is learning through means of 'play' which ranges from active-play that requires physical, verbal or mental engagement to pleasurable play that emphasises on enjoyment as a key feature. The manner in which children interact with one another and perform independently is learned from their surroundings, experiences and by parents and teachers. If an education system is conceptualised which utilises and manipulates play-based learning teach children, the many subjects they are required to learn. It will greatly impact the way things are done. No one child is alike. Every child learns differently and that is true for adults. By introducing play-based learning, we can maximise the academic standards by having more than one way to teach the same concepts.

Presently, the academic standards are maintained by a standard approach. This is aimed to teach kids discipline, obedience, respect and learning subjects such as science, math, reading, writing, art and physical education. Students are expected to enter a classroom and be taught to adhere to the rules and routines of each classroom with little disobedience present. This requirement for obedience lead many to research and inquire about classroom management skills and developmentally appropriate behaviours. However, not all students learn through this approach. This paper will also look into an appropriate means of educating young minds and asking readers to view from a child's perspective to understand the value of play-based learning. 


\section{Importance of Play-Based Learning}

Play-based learning allows students to engage in purposeful activities that will allow for the simulation of such experiences they are likely to encounter. This is generally defined as having the following four features: 1) It is usually voluntary; 2) It is intrinsically motivating, that is it is pleasurable for its own sake and is not dependent on external rewards; 3) It involves some level of activity, often physical, engagement; and 4) It is distinct from other behaviours by having a make-believe quality. Each feature leaves room for the fostering of strong metacognitive skills and the ability to build independence as well as co-dependency on their peers. ${ }^{2}$ Students benefit greatly from their play experiences through the innate learning method, educators can manipulate scenarios to teach children certain curriculum goals.

As mentioned by Rieber play and imitation are natural learning strategies where children are quick to grasp, ${ }^{2}$ which allows for educators to build meaningful experiences for children within the classroom through careful modeling of behaviours and opportunities of imitation and manipulation. Allowing students to manipulate their experiences is important for the child, as they will retain the information, they have gathered best in a personal manner that is meaningful to them. For this reason, students will work with their educators, peers and independently to meet the task's objective in a play-based learning classroom. This also allows students the opportunity to safely obtain other skills they will carry on into adolescence and adulthood within their academic setting, whilst being supported by their educator. It is crucial for students to gain opportunities to explore and learn major life skills such as problem-solving, independently or with peers. ${ }^{3}$ The failure to use these strategies, however, may not be related so much to age but to experience and the teachers' interventions can help even young children to develop some of the meta-components that are the strategies of successful learning

\section{The Educational Organisation}

Educational institutions are highly influenced by the culture the children are developing within. These influences include but are not limited to cultural norms and biases, societal structures and national changes. Each influence is carried into the classroom to then create a unique blend within the child's academic setting. Many children who enter the classroom for the first time are overwhelmed by the rules and routines of the classroom. As mentioned by Norris B Johnson, students who enter a Kindergarten classroom are overstimulated with the visuals that exist within the room. ${ }^{3}$ They are distracted by their surroundings and adjusting to the new changes from their previous academic experience in Pre-Kindergarten. The children are focused on completing one task as a means to begin another that they do not appreciate the work they have created. Children are accustomed to having a beginning and end to each activity they begin. Children are constantly searching for the next activity with little time to pause and reflect on their daily experiences or think about their goals for the upcoming days. Students require time to self-reflect and develop meaningful interpretations of the learning experiences throughout the day or week. ${ }^{4}$ As mentioned by Fisher, children develop their skill sets such as sensory-motor skills, representational skills and abstract skills gradually. ${ }^{4}$ Students will not learn these skill sets by simply being taught the right or wrong response to a situation or task. It is important for students and educators alike to learn the value of self-reflection.

\section{Self-Reflection}

Self-reflecting and creating meaningful interpretations encourage children to value the amount of work put into the process to achieve their short-term goal, such as a simple task. This is often utilised during a child's play opportunity. During this time children learn to appreciate the process that was placed into a short-term goal, allowing children to understand they must continue to build upon their work to achieve a larger, long-term goal. In addition, students will learn that quality requires work and self-reflection can make them feel more confident in their ability to perform academically and score well. This positively impacts their emotional reactions to grades and the academic grading system. According to Wilson and Gilbert, student's reactions will increase overtime and they will value the hard work and effort put into achieving good grades. ${ }^{5}$ As students have more meaningful feedback from their educators on a personal level, they will be better able to comprehend what is going on. This new approach would allow for children to psychologically benefit from the feedback they are given by their educators.

Children look forward to opportunities to play and explore their settings with their peers and educators. Students who engage in play-based practices are given the opportunity to work with their educators and families within their academic setting often display reduced behaviour issues. $^{6}$ Brotman et al discusses the importance of preventative interventions versus corrective interventions. ${ }^{7}$ Students who enter the classroom for the first time may be unsure of the many rules and routines that exist within a new setting. It is important for educators to encourage children to interact with one another positively. As mentioned by Garvis and Pendergast, "Social and emotional well-being aligns with holistic approaches to teaching and learning... in which children explore different elements of their identity (including social and emotional) through their play and relationships." 8 A holistic approach that is being encouraged within academic settings is play-based learning. Students who display behaviour challenges during their early educational experiences are more likely to drop out of school than their counterparts. Brotman et al expresses the need for intervention prior to the encounter of an issue. ${ }^{9}$ The intervention is play-based learning and utilising selfreflection as means to enhance the learning experience.

\section{Physical Development}

Children learning in an early childhood setting require much more than rote memory lessons and sedentary discipline as they work to prepare for their future. Those who are learning in early childhood classrooms require physical stimulation to ensure proper physical development throughout their early childhood years. Through play-based learning, students will holistically gain access to more fine and gross motor opportunities. ${ }^{9}$ Traditional teaching methods consist of students remaining obedient and sedentary with a great deal of oral teaching. Students are expected to then retain the information they are given and demonstrate their understanding of this information on a written exam. It is important for children to have opportunities to be physically 
active in their academic settings. Tactile learning will assist children to develop a deeper level of understanding of the material.

There is a recent increase in childhood obesity, as children are no longer as physically active as they once were. Childhood obesity is linked to health issues such as diabetes, high blood pressure among others later in life. Fortunately, teaching children to explore their settings and be active within their academic setting is a springboard for a healthier future. Teachers will give children the opportunity to create a healthier lifestyle, which will have a great health benefit. Play-based learning is a way for children to be active in their day-to-day activities, while learning how to remain focused on a given task. Lessons of discipline are often obtained through physical activity when children are in their early childhood years. Children learn turn-taking, sportsmanship, communication and leadership. It is important for children to learn how to work with one another and how to support one another. Allowing children to play games and sports is a great way for teachers to encourage children to learn these life skills that will benefit them throughout their lives.

\section{English Language Learners and Socialisation}

The use of play-based learning strongly supports the promotion of socialisation amongst the children and the development of language. There has been a recent increase in the number of students who enter the early education system as English as A Second Language Learners (ESL); also identified as English Language Learners (ELL). There has been a need for students to receive additional instruction from their educators as a means to prevent these learners from falling behind academically. ${ }^{10}$ Students enrolled in the public school system are required to demonstrate their knowledge and understanding of the material prior to entering the next grade. There are moments when those who require additional services such as ELL support do not receive the services they need. Many ELL students struggle to communicate with their educators and peers regarding academic material as they are learning to manage the languages appropriately, whilst simultaneously gaining exposure to the new written symbol system for English.10

The use of play-based learning allows for ELL students to communicate with their peers in a manner that is more encouraging. The use of play-based learning allows students to meet the goals of the curriculum in a holistic manner that requires communication with one another. The child who is an ELL in the academic system will gain the opportunity to visually understand the concept their peers are demonstrating, engage in the process of learning through play and receive auditory input of the information that is being shared amongst peers. In addition, the child will receive the added input of the educator who is manipulating the play situations for learning. This frontload of information for this child is beneficial to their learning experience, as they are learning in a holistic manner which completely emerges them in the culture, curriculum and academic system. The child will feel more comfortable expressing the information that has been acquired. Furthermore, the fear of the child falling behind academically will reduce as families will feel more confident that the educator is supporting their child in a manner that is most suitable and appropriate.
The use of play-based learning also promotes and supports the continued development of problem-solving, coping, understanding cultural differences, classroom etiquette, etc. As mentioned by Robinson and Zajicek, social competence can be defined as the ability of a child to successfully and appropriately select and achieve their interpersonal goals. ${ }^{1}$ Such goals may include making friends, being in a safe place and having a bond with their educator. Furthermore, Liu et al mentions "Language learners should develop their understanding of the convention of the language used by engaging in the kinds of language activity found in real life rather than by learning lists of rules."11 When these goals are sought and strengthened, students will learn to navigate their academic setting. Fortunately, playbased learning provides students with the opportunity to freely explore their settings and materials. Students will gain a level of comfortability within their academic setting that cannot be found in a traditional academic setting. It is difficult for a child to feel comfortable imitating actions they are unsure of. If a child is unable to stand and explore the classroom like a teacher, the child will replicate the actions of the teacher as one who is authoritative within the classroom and a student as one who is meant to remain obedient to the teacher. Giving students the opportunity to feel more comfortable to ask questions about their academic setting, directly influences student's willingness to take risks in their academic setting. Students will have gained the opportunity to explore the social constructs of their school and feel comfortable enough to challenge themselves by thinking of ways to contribute to their setting in a personal way. Each contribution of the child encourages the development of problem-solving, coping, etc. The creation of a personal space within their school makes children feel safe and welcome each day. The manner in which they choose to manipulate their environment encourages students to think of what works best for their academic needs.

\section{DISCUSSION}

The benefits of play-based learning outweigh the traditional methods of teaching. Not only will the element of meaningfulness be included in the work they do, but also the added health benefits. Learning can be healthy and the longevity of this method can prove to be beneficial both academically and for physical wellness.

Students who are working to complete Pre-Kindergarten are encouraged to continue fostering their understanding of independence, build social skills, social-emotional development, motor function, etc. It is incomprehensible to assume a child will have mastered these skills within the time span of one academic year. For this reason, it is necessary to continue this play-based mode of learning throughout the entirety of one's early childhood experiences (from birth to eight-years-old). Those enrolled in Pre-Kindergarten programs are given an ample amount of opportunities to express their knowledge of each content area through holistic means such as representational art, verbal exchange and creations with manipulatives. Teachers are required to document each child's expression of knowledge and utilise them as a justification of the child's progress of the curriculum goals. Allowing teachers to utilise this holistic approach to gathering data is more natural for the child and the teacher. Students are guaranteed to feel more 
comfortable with their assessments and teachers will feel more comfortable interacting with the children in a meaningful way. ${ }^{7}$ In addition, students will feel more valued for the innately creative display of their problem-solving abilities that were utilised to express the information they have obtained.12

Students from ages birth through eight-years-old learn most information through careful, manipulated actions within their environment. ${ }^{3}$ When a toddler first holds a piece of puzzle, they first observe the colour, shape and texture. Overtime, the toddler may seek to understand the purpose or meaning of this piece. This is the moment where an educator can intervene and offer guidance to this young mind. This is the push they need to complete the puzzle successfully. Without this experience, it would be difficult for the child to continue to grow and develop his or her problem-solving skill set. It is necessary for all children to receive these holistic experiences as they will mature and develop with the children overtime. As this child grows older, he or she will be familiar with the element of trial and error or logistically analyse the puzzle piece to understand the proper placing that will be required. This child will then seek to challenge their mind in a different way. Perhaps, the child is now in Kindergarten, learning about measurements. With the learned concept of how to manipulate a piece into an image, this same child may now utilise a ruler with the same manipulation. Learning that numbers and concrete materials represent meaning in a different way, and sometimes objects that are too large may not fit into small boxes unless they too can be manipulated, etc.

The element of play-based learning within the classroom is much more significant than envisioning children running amuck with no interference from their educators. Students will strive to achieve a goal in a challenging manner that will ignite an innate interest in the task. It is crucial for the educators to have the children self-reflect after to ensure the task completed was fully understood. This is what drives children to teach themselves the information they feel they must learn. Play-based learning is innate and occurs naturally. It is the goal of the educator to manipulate a child's play experiences to allow for the deep, meaningful, understanding of the academic goals to occur.

\section{CONCLUSION}

It is certainly not simple to predict the trajectory of each child's future. However, with proper guidance utilising the necessary developmental domains, one can greatly assist it. No matter the differences in opinions, children are benefited from receiving some type of education during their early development years. It is an early learning-based system designed to achieve long-term success in infant's lives. This platform is not only designed for educational purposes but also for developing language skills and interactions, selfreflection, sociable and so forth. This paper concludes the benefits of play-based learning and how it can greatly impact the course of a child's path in education. Self-reflection is another way to provide a greater impact on the meaningfulness of a certain method of education, so that it may be retained better in the child's mind. This increased memorisation skills that are needed for higher level classes. ESL classes conformed to play-based learning can completely revolutionise the way these children study.

\section{REFERENCES}

[1] Robinson CW, Zajicek JM. Growing minds: the effects of one-year school garden program on six constructs of life skills of elementary school children. Hort Technology 2005;15(3):453-7.

[2] Rieber LP. Seriously considering play: Designing interactive environments based on the blending of microworlds, simulations and games. Educational Technology Research \& Development 1996;44(2):4358.

[3] Kim B, Park H, Baek Y. Not just fun, but serious strategies: Using meta-cognitive strategies in gamebased learning. Computers and Education 2009;52(4):800-10.

[4] Fisher R. Thinking about thinking: developing metacognition in children. Early Child Development and Care 1998;141(1):1-15.

[5] Johnson NB. The material culture of public school classrooms: the symbolic integration of local schools and national culture. Anthropology \& Education Quarterly 1980;11(3):173-90.

[6] Williams JD. Why kids need to be bored: a case study of self-reflection and academic performance. Research in Middle Level Education 2006;29(5):1-17.

[7] Wilson TD, Gilbert DT. Affective forecasting knowing what to want. Current Directions In Psychological Science 2005;14(3):131-4

[8] Ginsburg KR. American Academy of Pediatrics Committee on Communications; American Academy of Pediatrics Committee on Psychosocial Aspects of Child and Family Health. The importance of play in promoting healthy child development and maintaining strong parent-child bonds. Pediatrics 2007;119(1):182-91.

[9] Lake VE, Pappamihiel NE. Effective practices and principles to support English language learners in the early childhood classroom. Childhood Education 2003;79(4):200-3.

[10] Barton GM, Baguley M, MacDonald A. Seeing the bigger picture: investigating the state of the arts in teacher education programs in Australia. Australian Journal of Teacher Education 2013;38(7):74-90.

[11] Fisher KW. A theory of cognitive development: the control and construction of hierarchies of skills. Psychological Review 1980;87(6):477-531.

[12] Brotman LM, Calzada E, Huang KY, et al. Promoting effective parenting practices and preventing child behavior problems in school among ethnically diverse families from underserved, urban communities. Child Development 2011;82(1):258-76.

[13] Garvis S, Pendergast D. Thinking differently about infants and toddlers: exploring the reflections of future Australian early childhood teachers in Australia. Australian Journal of Teacher Education 2015;40(4):117-31. 